\title{
Safety and efficacy of dalcetrapib on atherosclerotic disease using novel non-invasive multimodality imaging (dal-PLAQUE): a randomised clinical trial
}

\author{
Zahi A Fayad, Venkatesh Mani, Mark Woodward, David Kallend, Markus Abt, Tracy \\ Burgess, Valentin Fuster, Christie M Ballantyne, Evan A Stein, Jean-Claude Tardif, James \\ H F Rudd, Michael E Farkouh, and Ahmed Tawakol for the dal-PLAQUE Investigators \\ Translational and Molecular Imaging Institute and Department of Radiology, Mount Sinai School \\ of Medicine, New York, NY, USA (Prof Z A Fayad PhD, V Mani PhD); Cardiovascular Institute, \\ Mount Sinai School of Medicine, New York, NY, USA (Prof Z A Fayad, Prof V Fuster MD, M E \\ Farkouh MD); George Institute, University of Sydney, Sydney, Australia (Prof M Woodward PhD); \\ F Hoffmann-La Roche Ltd, Basel, Switzerland (D Kallend MB BS, M Abt PhD); Hoffmann-La \\ Roche Inc, Nutley, New Jersey, NJ, USA (T Burgess MSc); Centro Nacional de Investigaciones \\ Cardiovasculares (CNIC), Madrid, Spain (Prof V Fuster); Baylor College of Medicine, Methodist \\ DeBakey Heart and Vascular Center, Houston, TX, USA (Prof C M Ballantyne MD); Metabolic \\ and Atherosclerosis Research Center, Cincinnati, OH, USA (Prof E A Stein MD); Montreal Heart \\ Institute, Université de Montréal, Montréal, QC, Canada (Prof J-C Tardif MD); Division of \\ Cardiovascular Medicine, University of Cambridge, Cambridge, UK (J H F Rudd MD); Peter Munk \\ Cardiac Centre and Li Ka Shing Knowledge Institute, Toronto, ON, Canada (M E Farkouh); and \\ Harvard Medical School and Massachusetts General Hospital, Boston, MA, USA (A Tawakol MD)
}

\section{Summary}

\begin{abstract}
Background-Dalcetrapib modulates cholesteryl ester transfer protein (CETP) activity to raise high-density lipoprotein cholesterol (HDL-C). After the failure of torcetrapib it was unknown if HDL produced by interaction with CETP had pro-atherogenic or pro-inflammatory properties. dalPLAQUE is the first multicentre study using novel non-invasive multimodality imaging to assess structural and inflammatory indices of atherosclerosis as primary endpoints.
\end{abstract}

Methods-In this phase 2b, double-blind, multicentre trial, patients (aged 18-75 years) with, or with high risk of, coronary heart disease were randomly assigned (1:1) to dalcetrapib $600 \mathrm{mg} /$ day

Correspondence to: Dr Zahi A Fayad, Mount Sinai School of Medicine, Departments of Radiology and Medicine (Cardiology), Translational and Molecular Imaging Institute, One Gustave L Levy Place, Box 1234, New York, NY 10029, USA,

zahi.fayad@mssm.edu.

Contributors

The dal-PLAQUE Executive Committee and VM participated in the design of the study and the interpretation of data. The sponsor participated in discussions regarding design and conduct of the study and provided logistical support during the trial. All authors had full access to all the data. Data were assessed jointly by the Executive Committee and the sponsor. Exploratory analyses were done by ZAF, VM, AT, and MW. The first draft of the manuscript was prepared by ZAF and VM, with edits and revisions provided by all authors. All authors have read and approved the final version. All authors had final responsibility for the decision to submit for publication.

Conflicts of interest

VM and VF declare that they have no conflicts of interest.

See Online for webappendix 
or placebo for 24 months. Randomisation was done with a computer-generated randomisation code and was stratified by centre. Patients and investigators were masked to treatment. Coprimary endpoints were MRI-assessed indices (total vessel area, wall area, wall thickness, and normalised wall index [average carotid]) after 24 months and ${ }^{18} \mathrm{~F}$-fluorodeoxyglucose $\left({ }^{18} \mathrm{~F}-\mathrm{FDG}\right) \mathrm{PET} / \mathrm{CT}$ assessment of arterial inflammation within an index vessel (right carotid, left carotid, or ascending thoracic aorta) after 6 months, with no-harm boundaries established before unblinding of the trial. Analysis was by intention to treat. This trial is registered at ClinicalTrials.gov, NCT00655473.

Findings -189 patients were screened and 130 randomly assigned to placebo (66 patients) or dalcetrapib (64 patients). For the coprimary MRI and PET/CT endpoints, CIs were below the noharm boundary or the adverse change was numerically lower in the dalcetrapib group than in the placebo group. MRI-derived change in total vessel area was reduced in patients given dalcetrapib compared with those given placebo after 24 months; absolute change from baseline relative to placebo was $-4.01 \mathrm{~mm}^{2}(90 \% \mathrm{CI}-7.23$ to -0.80 ; nominal $\mathrm{p}=0 \cdot 04)$. The PET/CT measure of index vessel most-diseased-segment target-to-background ratio (TBR) was not different between groups, but carotid artery analysis showed a 7\% reduction in most-diseased-segment TBR in the dalcetrapib group compared with the placebo group ( -7.3 [90\% CI -13.5 to -0.8$]$; nominal $\mathrm{p}=0.07$ ). Dalcetrapib did not increase office blood pressure and the frequency of adverse events was similar between groups.

Interpretation-Dalcetrapib showed no evidence of a pathological effect related to the arterial wall over 24 months. Moreover, this trial suggests possible beneficial vascular effects of dalcetrapib, including the reduction in total vessel enlargement over 24 months, but long-term safety and clinical outcomes efficacy of dalcetrapib need to be analysed.

Funding-F Hoffmann-La Roche Ltd.

\section{Introduction}

The improvement of cardiovascular outcomes in patients with, or at high risk of, atherosclerotic disease is needed, despite significant reductions in events achieved with lowdensity lipoprotein cholesterol (LDL-C)-lowering therapies, particularly statins. ${ }^{1-3}$ One potential approach to reduce atherosclerotic plaque burden is to raise high-density lipoprotein cholesterol (HDL-C), ${ }^{4,5}$ for which epidemiological studies have consistently shown an inverse relation with risk of coronary artery disease. ${ }^{6,7}$ Even in statin-treated patients, low HDL-C plasma concentrations are an independent risk factor for cardiovascular events, ${ }^{8,9}$ whereas higher levels of HDL-C are associated with reduced plaque progression ${ }^{10}$ and reduced frequency of cardiovascular events. ${ }^{11}$

Drugs that act on cholesteryl ester transfer protein (CETP) can result in substantial increases in serum HDL-C. A previously investigated CETP inhibitor, torcetrapib, effectively increased HDL-C, but was associated with an increase in mortality, ${ }^{12}$ subsequently thought to be due to compound-specific off-target effects, such as increases in blood pressure and vascular inflammation. ${ }^{13}$ Dalcetrapib is a novel modulator of CETP activity that increases HDL-C. ${ }^{14-16}$ To date, its tolerability has been reassuring with no evidence of clinically relevant increases in blood pressure. ${ }^{15-17}$ Preclinical experiments in rabbits showed a 
decrease in atherosclerosis with dalcetrapib; ${ }^{18}$ however, the direct clinical effects of dalcetrapib on atherosclerosis are unknown.

MRI and PET/CT are promising techniques for assessment of vascular morphology and vascular inflammation, respectively, and for quantification of the effects of drug interventions on plaque stability and burden. ${ }^{19-22}$ By directly measuring the effect on the vessel wall of cumulative cardiovascular risk factors combined, ${ }^{23,24}$ these non-invasive imaging techniques can serve as valuable biomarkers. ${ }^{25} \mathrm{~A}$ multimodality approach with these two techniques to assess dalcetrapib's effects was therefore used in dal-PLAQUEMRI to measure established classic variables of plaque morphology, and assess the progression or regression of atherosclerosis, and PET/CT measurement of ${ }^{18} \mathrm{~F}$ fluorodeoxyglucose $\left({ }^{18} \mathrm{~F}-\mathrm{FDG}\right)$ uptake to identify plaque inflammation. This 24-month dalPLAQUE trial is the longest placebo-controlled active-drug MRI study until now, as well as the first to use non-invasive multimodality imaging for primary endpoints. The primary aim of the study was to show, with a dual-imaging approach, whether dalcetrapib causes an increase in atherosclerotic plaque progression or vascular inflammation compared with placebo.

\section{Methods}

\section{Study design}

This phase $2 \mathrm{~b}$ double-blind, randomised, placebo-controlled study was investigator initiated with the final study protocol designed in collaboration with the sponsor (F Hoffmann-La Roche Ltd). This study was done at 11 centres in Canada and the USA, in compliance with the principles of the Declaration of Helsinki and according to Good Clinical Practice guidelines. The protocol was reviewed and approved by the institutional review board of every centre. All participants provided written informed consent before performance of any study procedures. Methods have been previously published ${ }^{26}$ and are briefly described in this report.

\section{Patients}

Patients were screened between Feb 18, 2008, and Aug 29, 2008. We included men and women aged 18-75 years, with previous known coronary heart disease or at high risk of coronary heart disease (diabetes or a 10-year risk of coronary heart disease events $>20 \%$ by Framingham Risk scoring), ${ }^{27}$ triglyceride concentrations of $400 \mathrm{mg} / \mathrm{dL}$ or lower ( $\leq 4.5$ $\mathrm{mmol} / \mathrm{L}$ ), and carotid or aortic arterial wall (target) to background (blood) ratio (TBR) of 1.6 or higher, ${ }^{28}$ as identified by ${ }^{18}$ F-FDG uptake measured by PET/CT during the screening period. Patients were clinically stable and receiving appropriate and stable treatment with a statin or other LDL-C lowering drugs with LDL-C concentrations of $100 \mathrm{mg} / \mathrm{dL}$ or lower $(<2.6 \mathrm{mmol} / \mathrm{L})$ unless receiving maximum tolerated doses of therapy or intolerant to statins.

Exclusion criteria included concomitant treatment with fibrates or nicotinic acid, presence of uncontrolled blood pressure or diabetes $\left(\mathrm{HbA}_{1 \mathrm{c}}>10 \%\right)$, recent ( $<3$ months) clinically significant coronary or cerebral vascular event, diagnosis of familial hypercholesterolaemia, 
or a glomerular filtration rate lower than $30 \mathrm{~mL} / \mathrm{min}$. Other reasons for exclusion were standard for this type of trial. ${ }^{26}$

\section{Randomisation and masking}

Randomisation occurred between March 25, 2008, and Nov 7, 2008. Patients were assigned according to a computer-generated global randomisation code, stratified by centre, to receive either dalcetrapib $600 \mathrm{mg} /$ day or placebo for 24 months (ratio 1:1). Blinding was maintained through matching placebo and dalcetrapib tablets, and by withholding information about HDL-C concentrations from the investigative teams and participants.

\section{Procedures}

Patients entered into a prerandomisation, screening phase of up to 8 weeks, to allow for adjustments in lipid-lowering therapy, to achieve stable LDL-C concentrations lower than $100 \mathrm{mg} / \mathrm{dL}$ ( $2.6 \mathrm{mmol} / \mathrm{L})$ unless taking maximum tolerated doses of therapy. During this period, patients underwent ${ }^{18}$ F-FDG-PET/CT, and those with average maximum TBR of 1.6 or higher (in an index vessel-ie, either right carotid, left carotid, or ascending aorta) were eligible for randomisation. Baseline MRI was done at the randomisation visit within 2 weeks of the screening PET/CT. Follow-up imaging was done at 3 and 6 months (PET/CT) and at 6,12 , and 24 months (MRI) after randomisation.

We took blood samples for measurement of concentrations of total cholesterol, triglycerides, HDL-C, LDL-C, and lipoprotein subfractions at baseline (randomisation), 1 month, 3 months, and then at 3-month intervals until 24 months, and for apolipoproteins B and A1, at baseline, every 3 months until 18 months and then again at 24 months. Lipid and apolipoprotein results, other than LDL-C concentrations, remained blinded to study participants and staff from the randomisation visit. We assessed vital signs (blood pressure, heart rate, and temperature), adverse events, urinalysis, serum biochemistry, haematology, and coagulation at baseline, after 1 month and then at 3-monthly intervals between months 3 and 24. We did electrocardiographs (ECG) at baseline and after 1, 12, and 24 months. A safety follow-up visit was scheduled 14 days after the end of treatment.

Details of imaging procedures and analyses have been published previously. ${ }^{26}$ In brief, we did MRI of the carotid arteries and abdominal aorta using previously validatedimagingmethods. ${ }^{26,29,30}$ Similarly, ${ }^{18} \mathrm{~F}$-FDG-PET/ CT imaging of the carotid arteries and ascending thoracic aorta was undertaken according to validated, reproducible methods. ${ }^{20,28,31}$ Mean and maximum standardised uptake value (SUV) was measured along the carotids and ascending aorta at about $5 \mathrm{~mm}$ intervals, in axial orientation. SUV is a widely used PET quantifier, calculated as a time-corrected and dose-corrected ratio of tissue radioactivity divided by bodyweight (webappendix p 12). We calculated TBR from the ratio of SUV of the artery compared with background venous activity ${ }^{26}$ and recorded values for the individual vessels (aorta and mean right and left carotid artery) with previously reported methods. ${ }^{20,28,31}$ MR and PET/CT images were analysed at the core laboratory by masked, experienced readers, two for MRI data and two for PET/CT data. 


\section{Endpoints}

MRI and PET/CT results were the prespecified coprimary imaging endpoints for this study ${ }^{26}$ The predefined, primary MRI endpoint was structural changes in the arterial wall, measured as absolute or percent change, or both, from baseline in four indices: total vessel area, wall area, wall thickness, and wall area/total vessel area ratio (normalised wall index), based on the average of the right and left carotids after 12 months. ${ }^{21,30,32}$ However, on the basis of the reports available at the time, the Executive Committee decided (Nov 13, 2010) before data lock and unblinding, to extend the timepoint for primary MRI endpoint of noharm to 24 months of treatment to capture possible longer-term effects (webappendix p 9). Secondary MRI endpoints were change from baseline in the MRI-derived variables of "atherosclerotic plaque burden" after 6 and 12 months. Other exploratory endpoints were specified in the protocol. ${ }^{26}$

The primary PET/CT endpoint (assessing vascular inflammation) was absolute or percent change, or both, from baseline in arterial wall ${ }^{18} \mathrm{~F}-\mathrm{FDG}$ uptake (assessed as the TBR) within the index vessel (either right carotid, left carotid, or ascending thoracic aorta) after 6 months. Additionally, we did a separate, exploratory analysis on the carotid vessels only (using the average carotid artery values) to allow a comparison between measured PET/ CT activity and primary structural MRI endpoints (which were carotid-based).

The predefined primary PET/CT variable used to assess drug effect on vascular inflammation was change in TBR within the most diseased segment at 6 months (compared with baseline). The most diseased segment is defined as the $1.5 \mathrm{~cm}$ segment within the index vessel that shows the highest PET/CT activity at baseline, and is calculated as a mean of maximum TBR values derived from three contiguous axial segments (most-diseasedsegment TBR; webappendix p 13). Secondary endpoints include 3-month observations for change in most diseased segment TBR and 3-month and 6-month observations for change in: (1) mean of maximum TBR (meanMax TBR), which is the average of maximum TBR values derived at every axial section that composes the vessel; and (2) mean of mean TBR (meanMean TBR), which is the average of mean TBR values derived at every axial section that composes the vessel. Most-diseased-segment TBR was chosen over meanMean and meanMax TBR values since the latter two represent a mixture of diseased as well as lessdiseased vessel regions and theoretically could represent vascular endpoints that are less sensitive for detection of drug effect. Additionally, most-diseased-segment TBR is, of the three potential PET/CT variables assessed herein, most similar to that used by Tahara and colleagues $^{33}$ in their assessment of statin effects.

Biochemical endpoints were change from baseline after 3, 12, and 24 months in biomarkers of inflammation, oxidation, and cardiovascular risk: high sensitivity $\mathrm{C}$-reactive protein (hsCRP), lipoprotein-associated phos- pholipase $\mathrm{A}_{2}$ (Lp-PLA 2 ), interleukin 6, soluble Pselectin (sP-selectin), soluble E-selectin (sE-selectin), soluble intracellular adhesion molecule, soluble vascular cell adhesion molecule, matrix-metalloproteinase 3 and 9 , myeloperoxidase, tissue plasminogen activator, and antigen and activity of plasminogen activator inhibitor 1 . 


\section{Safety assessments}

Safety was assessed by vital signs, reports of adverse events, laboratory data, and ECGs.

Prespecified clinical cardiovascular endpoints were monitored as a component of the overall dal-HEART programme and adjudicated by an independent clinical endpoint committee. ${ }^{26}$

\section{Statistical analysis}

The statistical analysis is detailed in the webappendix (p 9).

This trial is registered with ClinicalTrials.gov, number NCT00655473.

\section{Role of funding source}

The sponsor participated in discussions about design and conduct of the study and provided logistical support during the trial. Data were assessed jointly by the sponsor and the executive committee. All authors had full access to all the data in the study and had final responsibility for the decision to submit for publication.

\section{Results}

Of 189 patients screened, 130 were randomly assigned to either placebo or dalcetrapib 600 $\mathrm{mg}$ /day (figure 1). Baseline demographics including risk factors of atherosclerotic disease and coronary heart disease were generally balanced between the two groups (table 1). More patients had coronary heart disease in the dalcetrapib group whereas more had peripheral arterial disease in the placebo group. Despite a slight imbalance in statin use, LDL-C concentrations were well matched in both groups at baseline. Baseline HDL-C concentrations were slightly lower in the dalcetrapib group (table 1).

In the dalcetrapib group, concentrations of HDL-C increased by $31 \%$ and those of apolipoprotein A1 increased by $10 \%$ at 24 months (mean change from baseline; table 2). Dalcetrapib mean percent changes from baseline relative to placebo were $+26.9 \%$ (90\% CI $20.0-33.9 \%)$ for HDL-C and $+6.8 \%(2 \cdot 5-11 \cdot 1)$ for apolipoprotein A1. Median change in hsCRP was $+33 \%$ after 24 months with dalcetrapib and was unchanged with placebo (table 2). Lp-PLA 2 mass decreased from baseline after 24 months with placebo (-0.36\%) and increased with dalcetrapib (+9.03\%; webappendix pp 1-2). CETP activity decreased and CETP mass increased with dalcetrapib compared with placebo at 24 months; mean percent changes were $-55.5 \%(90 \% \mathrm{CI}-64 \cdot 4$ to $-46 \cdot 6)$ for CETP activity and $+77 \cdot 2 \%$ ( $+67 \cdot 1$ to $+87 \cdot 3$ ) for CETP mass.

No evidence of proatherogenic effect of dalcetrapib therapy was recorded, in terms of plaque burden compared with placebo as assessed by MRI after 24 months (table 3). In the dalcetrapib group, changes from baseline relative to placebo were $-4.01 \mathrm{~mm}^{2}(90 \% \mathrm{CI}$ -7.23 to -0.80 ) for total vessel area, $-2.20 \mathrm{~mm}^{2}(-4.54$ to 0.13 ) for wall area, and $+0.60 \%$ $(-1 \cdot 2$ to $2 \cdot 5)$ for normalised wall index. All three variables were under the predefined limits of no harm. The dalcetrapib change from baseline relative to placebo in mean wall thickness was $-0.03 \mathrm{~mm}(-0.11$ to 0.04$)$, and the upper CI was beyond the predefined limit of no harm. However, numerically, there was less increase in wall thickness with dalcetrapib than with placebo after 24 months (table 3). 
PET/CT-derived results showed no evidence of increased vascular inflammation with dalcetrapib compared with placebo after 6 months. For the primary endpoint of mostdiseased-segment TBR of the index vessel, mean change from baseline was -0.26 (SE 0.08) for placebo and $-0 \cdot 19$ (SE 0.08) for dalcetrapib ( $\mathrm{p}=0.51$; table 3 ). Thus, the dalcetrapib change from baseline relative to placebo was 0.07 (90\% CI -0.11 to 0.25 ) after 6 months and was under the predefined limit of no harm. We did sensitivity analyses to investigate the potential effect of missing post-baseline data; the missing values did not qualitatively affect the overall interpretation of the imaging data (data not shown). Data for the coprimary endpoints (change from baseline to 6 months for most-diseased-segment TBR and change from baseline to 12 and 24 months for MRI indices) were analysed for the defined perprotocol population and results were qualitatively similar to those reported for the intention to-treat population (webappendix p 7).

The total vessel area (average carotid) was decreased with dalcetrapib compared with placebo after 24 months (figure 2; webappendix p 19). An example of reduced total vessel area in a dalcetrapib-treated patient is shown in the webappendix (p 14). There was a numerical reduction in wall area with dalcetrapib compared with placebo after 24 months (table 4, webappendix p 15). The absolute change and mean percent change from baseline after 24 months for normalised wall index (webappendix p 16), as well as the individual patient data for absolute change in average carotid total vessel area by MRI are shown in the webappendix ( $\mathrm{p} 17)$.

Within the index vessel, absolute or percent changes from baseline in index vessel measures of most-diseased-segment TBR, between placebo and dalcetrapib after 3 or 6 months did not differ (table 4). However, the carotid arteries analysis showed reductions in absolute and percent changes from baseline in PET/CT measures with dalcetrapib compared with placebo (table 5, figure 3, webappendix p 20). The average carotid artery most-diseased-segment TBR remained unchanged in the placebo group but was significantly reduced in the dalcetrapib group (figure 3). Compared with placebo, dalcetrapib was associated with a nonsignificant reduction in most-diseased-segment TBR after correcting for baseline and similar trends were observed for percent change in average carotid most-diseased-segment TBR (figure 3). Individual patient data are shown in the webappendix (p 18). Other PET data are shown in the webappendix (pp 4,6).

Taking into account all patients without regard to treatment assignment, increases in HDL-C concentrations correlated with decreases in TBR-assessed arterial inflammation $(r=-0 \cdot 30$, $\mathrm{p}=0.04)$. When patients were classified according to tertiles of HDL-C change, a $4.3 \%$ reduction in arterial inflammation (most-diseased-segment TBR), was recorded with every increase in HDL-C tertile (slope $-4.3 \%$ [90\% CI -7.7 to -0.8$]$, $\mathrm{p}=0.04$; figure 4). However, given the fact that the lowest tertiles are exclusively occupied by patients in the placebo group and the highest tertiles in the dalcetrapib group, the relative influence of HDL raising and drug effect (independent of HDL-C) on arterial inflammation remains unclear. However, when changes in HDL-C concentrations were compared with structural changes by MRI, no significant correlations were seen. Specifically, the correlations $(r)$ between percent change in HDL-C concentration versus percent change in MRI variables (24-month 
-baseline), were $-0.19(\mathrm{p}=0.09)$ for total vessel area, $-0.08(\mathrm{p}=0.50)$ for wall area, 0.06 $(\mathrm{p}=0.60)$ for wall index, and $-0.02(\mathrm{p}=0.86)$ for wall thickness.

Reductions in arterial inflammation after 6 months as identified by PET/CT (final PET/CT observation) seemed to be related to a subsequent reduction in the rate of progression of total vessel area after 24 months (final MRI observation). Patients' data were classified according to tertiles of change in total vessel area, whereby the highest tertile represented the patients that had the greatest increase in total vessel area in the course of the study. The association between increases in most-diseased-segment TBR across the tertiles of increases in total vessel area was significant $(\mathrm{p}=0.03)$. Further, patients with the greatest increase in carotid total vessel area by MRI (highest tertile) after 24 months had had an increase in vascular inflammatory signal in the initial 6 months (most-diseased-segment TBR by PET/ $\mathrm{CT}$ ), whereas those with smaller changes in carotid total vessel area by MRI (lowest two tertiles) had a reduction in most-diseased-segment TBR (percent change in MDS TBR 6.6\% [90\% CI $0 \cdot 8-12 \cdot 4)$ and $-6 \cdot 7 \%$ [ $-12 \cdot 3$ to $-1 \cdot 1]$ for highest tertile total vessel area by MRI versus others, respectively, $\mathrm{p}=0 \cdot 01$, figure $4 \mathrm{~B}$ ).

The rates and reasons of withdrawal were similar in both treatment groups. In total, 14 (22\%) of 65 patients given placebo and $10(16 \%)$ of 63 patients given dalcetrapib discontinued, seven (11\%) and five (8\%) for safety reasons, respectively. A clinical event (death) leading to discontinuation occurred in two placebo-treated patients (one death caused by coronary heart disease and one by electromechanical dissociation) and in one dalcetrapibtreated patient (caused by metastatic cancer). The dalcetrapib group had fewer drug-related adverse events, and discontinuations because of drug-related adverse events or rates of serious adverse events did not differ between treated and control groups (table 6).

Laboratory changes, including liver transaminases and creatine phosphokinase assessments, did not differ between placebo and dalcetrapib; creatine phosphokinase was raised in five (8\%) patients in the placebo group and in six (10\%) patients in the dalcetrapib group. Increases in concentrations of aspartate aminotransferase were reported in three patients given dalcetrapib and one patient given placebo.

Vital signs did not differ between groups. At baseline, mean systolic and diastolic blood pressure (cuff measurements)were, respectively,122.4 (SD15.1) $\mathrm{mmHg}$ and 71.9 (8.7) mm $\mathrm{Hg}$ for placebo and 119.5 (14.5) $\mathrm{mm} \mathrm{Hg}$ and 72.8 (9.2) $\mathrm{mm} \mathrm{Hg}$ for dalcetrapib; after 24 months, mean systolic and diastolic blood pressure values were 126.1 (18.7) $\mathrm{mm} \mathrm{Hg}$ and 72.3 (12.1) $\mathrm{mm} \mathrm{Hg}$ for placebo and 119.1 (12.6) $\mathrm{mm} \mathrm{Hg}$ and 69.8 (8.7) $\mathrm{mm} \mathrm{Hg}$ for dalcetrapib. A similar number of patients in both groups had increases or decreases of both diastolic and systolic blood pressure above and below the predefined thresholds during the study (table 6). More adjudicated cardiovascular events occurred in the placebo group than in the dalcetrapib group (table 6).

\section{Discussion}

The primary endpoints for dal-PLAQUE showed dalcetrapib did not increase plaque progression over 24 months or inflammation in the vessel wall over 6 months compared 
with placebo. For the coprimary PET/CT and MRI endpoints, CIs were below the no-harm boundary or the adverse change was numerically lower in the dalcetrapib group than in the placebo group. These data suggest dalcetrapib might be associated with favourable vascular changes. After 24 months, total vessel area increased less with dalcetrapib than with placebo $(\mathrm{p}<0 \cdot 05)$ and was accompanied by a reduction in wall area $(\mathrm{p}=0 \cdot 12)$. These imaging results were recorded in the context of an early increase in HDL-C concentration of $31 \%$ and other potentially beneficial changes in the lipid profile, which were maintained during 24 months. ${ }^{34,35}$ Moreover, carotid vessel analysis of ${ }^{18}$ F-FDG-PET/CT data showed a reduction in vascular inflammation over 6 months in the dalcetrapib group relative to the placebo group, which seemed to be correlated with an increase in HDL-C concentrations. In another exploratory analysis, reductions in the inflammatory signal in the carotids measured with PET/CT at 6 months were noted to be associated with a reduction in the rate of increase in total vessel area by MRI at 24 months. Hence, taken together, the data suggest that dalcetrapib might reduce adverse structural changes within the blood vessel via a mechanism relating to reduced vascular inflammation and increased HDL-C concentrations.

In light of the ongoing debate about the proatherogenicity or anti-atherogenicity of CETP activity, ${ }^{4,36-41}$ the multimodality imaging techniques used in dal-PLAQUE were deemed a useful biomarker approach to increase confidence that CETP modulation with dalcetrapib does not cause short-term harm while results from larger outcomes trials were pending. ${ }^{42}$ Studies with these dual imaging techniques could be done in sample sizes that are an order of magnitude smaller than is typical for coronary intravascular ultrasound (IVUS) or ultrasound carotid artery intima media thickness (cIMT) studies. ${ }^{18}$ F-FDG-PET is a noninvasive measure of vessel-wall inflammation able to differentiate between symptomatic and asymptomatic carotid artery plaques, ${ }^{43}$ exhibits excellent reproducibility, ${ }^{20}$ and is predictive of both older ( $>6$ months) and recent ( $<6$ months) cardiovascular disease history. ${ }^{44}$ Consequently, this method has become useful for assessment of effcacy of antiinflammatory drug treatment or lifestyle change. ${ }^{33,45}$ Conversely, the predictive value for future cardiovascular events of vessel wall morphometrics by MRI has not yet been examined in a long-term study. Vessel wall thickness by MRI is highly correlated with ultrasound cIMT, ${ }^{46,47}$ however, so it is to be expected that the predictive value of MRI would be similar.

Moreover, change in total vessel area over time may quantify vascular remodelling changes that occur as integral processes in atherosclerosis. Vascular enlargement (increase over time in total vessel area) has been shown to occur during atheroma accumulation (often referred to as positive remodelling). ${ }^{48}$ Enlarged athero-sclerotic arteries are more unstable and likely to be associated with acute coronary syndromes. ${ }^{49}$ In our study, increase in total vessel area over time in the placebo group seemed greater than increase in wall area, which might be evidence of excessive, maladaptive vascular enlargement that could render the arteries more vulnerable. This possibility is supported by the finding that greater increase in total vessel area on MRI seemed to be related with more vascular inflammation on PET/CT, as measured by most-diseased-segment TBR. Interestingly, dalcetrapib seemed to attenuate this maladaptive vascular enlargement (ie, reduced the increase in total vessel area over time) accompanied by slowed atheroma burden accumulation (ie, reduced increase in wall area over time). 
Results of imaging trials of statins and other lipid-modifying or blood-pressure-lowering therapies ${ }^{50-53}$ suggest that dal-PLAQUE data are consistent with what is known about the natural pathobiology of atherosclerosis. ${ }^{48,54-56}$ Benefits of lipid-altering therapy on plaque burden in terms of slowing disease progression might be recorded following 12-18 months of therapy, ${ }^{50}$ but evidence of disease regression generally requires at least 24 months of therapy. In the ORION study, ${ }^{57}$ regression on MRI required at least 2 years of intensive statin treatment.

An interesting finding of the study was the apparent disparity between systemic inflammation as measured by hsCRP and local vascular inflammation as measured by FDG PET. This issue has been observed in other studies, which have reported inconsistent relations between the two variables. ${ }^{58,59}$ These findings highlight that the blood and imaging biomarkers of inflammation might provide substantially different information about the vascular inflammatory milieu, the exact nature of which remains incompletely elucidated.

Results of standard safety assessments in dal-PLAQUE are favourable for the clinical profile of dalcetrapib. No imbalances in vital signs were recorded between placebo and dalcetrapib groups, including office measurements of blood pressure. Ambulatory monitoring of blood pressure is being assessed in dal-VESSEL, ${ }^{60}$ which will provide more definite findings on dalcetrapib's safety in this regard. The numbers and types of adverse events and rates of and reasons for withdrawal were similar between groups, consistent with previous reports. ${ }^{15}$ Inflammatory biomarker values did not differ between groups apart from an increase in Lp$\mathrm{PLA}_{2}$ mass in the dalcetrapib group. This increase might portray a change typically observed when the lipid profile shifts to a greater abundance of HDL particles ${ }^{61}$ or might be associated with its proposed dual role depending on the location of Lp-PLA 2 on antiatherogenic (HDL) or pro-atherogenic (LDL/very LDL) particles. ${ }^{62} \mathrm{Few}$ cardiovascular events occurred in this trial; adjudicated cardiovascular events were recorded for seven patients in the placebo group and two patients receiving dalcetrapib.

dal-PLAQUE has limitations. The pre-specified analysis plan stated that no correction would be made for multiple comparisons because of the exploratory nature of the analyses. However, since many significance tests are reported in this report, nominal p values should be interpreted with caution. It is noteworthy that the favourable results recorded on PET/CT (changes in most-diseased-segment TBR with dalcetrapib, association between increased HDL-C concentration and reduced TBR, and association between reduced TBR and subsequent attenuation in change in total vessel area on MRI) were recorded in the carotid artery but not in the index vessel analysis. Since the index vessel data were mainly taken from the ascending aorta, it is conceivable that the imaging technique is more sensitive to detection of treatment effect when applied to the carotids. To assess the potential effect of image quality, we did a post-hoc analysis during which data from image sets prospectively deemed marginal were removed from the index segment analysis. In that analysis, the index vessels showed a numerically greater reduction in TBR with dalcetrapib compared with placebo (data not shown). This post hoc analysis places the index vessel analysis results more in-line with carotid data and suggests the observed differences (neutral $v s$ positive response to therapy) might be due more to technical rather than biological factors. 
The potential that enrichment for arterial inflammation during the screening phase might have confounded the results of this study should be considered, since patients were excluded from randomisation if their baseline PET signal was low. However, the threshold for excluding patients because of a low PET signal was designed to exclude only the minority of atherosclerotic patients without significant arterial inflammation. We chose the TBR threshold of 1.6 because values lower than that value correlate with insignificant carotid atherosclerotic plaque macrophage infiltration $(<5 \%),{ }^{28}$ a level of inflammation that is seen after high-dose statin therapy. ${ }^{63}$ With this cutoff, only $14 \%$ of initially screened patients were excluded, thus most of them passed this screening threshold. Accordingly, the potential effect of enrichment is minimum. Additionally, regression to the mean should be taken into account. However, the individual patient plots inform helpfully with little evidence of an issue. Moreover, statistical analyses of PET and MRI treatment effects have controlled for baseline values.

Percent change in HDL-C or baseline HDL-C was not correlated with MRI indices of plaque burden. However, change in HDL-C after 6 months seemed to be inversely correlated with change in most-diseased-segment TBR by PET/CT over the same period. Furthermore, changes in the PET/CT signal after 6 months seemed to be correlated with subsequent changes in MRI-determined total vessel area after 24 months. These results support the hypothesis that HDL-C raising via CETP modulation might provide an early antiinflammatory effect that could in turn relate to favourable structural vascular changes. However, it is important to note that the analyses that delineated those findings were exploratory and additional study is warranted.

In conclusion, the results from this non-invasive multimodality imaging clinical trial of dalcetrapib compared with placebo showed no evidence of a pathological effect of this novel CETP modulator. Moreover, MRI provided evidence of a lower increase in total vessel area after 24 months in patients given dalcetrapib than in those given placebo. Additionally, PET/CT imaging provided an observation of a link between increases in HDL-C concentrations, reductions in vascular inflammation, and subsequent reductions in structural vascular changes. Two large ongoing clinical trials of dalcetrapib, dal-PLAQUE 2, assessing athero-sclerotic disease progression by coronary IVUS and carotide B-mode ultrasound (cIMT) ${ }^{25}$ and dal-OUTCOMES, ${ }^{64}$ assessing cardiovascular morbidity and mortality, will provide further insights into the therapeutic effects of dalcetrapib. The imaging methods used in dal-PLAQUE were used to detect the effects of dalcetrapib on vascular endpoints; confirmation of the long-term safety and clinical efficacy of dalcetrapib awaits the completion of dal-OUTCOMES.

\section{Supplementary Material}

Refer to Web version on PubMed Central for supplementary material.

\section{Acknowledgments}

This study was funded by F Hoffmann-La Roche Ltd. Editorial assistance was provided by Prime Healthcare during the preparation of this report and funded by F Hoffmann-La Roche Ltd. We thank Jan Bucerius, Sarayu Ramachandran, Dan Samber, and Claudia Calcagno, from Mount Sinai School of Medicine and Translational and 
Molecular Imaging Institute, for their support in data analysis. We thank Giulietta Campece and Joseph Pozza from Hoffmann-La Roche Inc, for operational support during the study, and the help of Steve Hurley and the dalPLAQUE project team from Quintiles.

ZAF has received research grants from Roche, GlaxoSmithKline, Merck, VBL Therapeutics, Novartis, BristolMyers Squibb, and Via Pharmaceuticals, and honoraria from Roche. MW has received honoraria from Roche. DK and MA are employees of F Hoffmann-La Roche Ltd and receive share options. TB is an employee of F HoffmannLa Roche Inc. CMB has received grant or research support (paid to institution, not individual) from Abbott, AstraZeneca, Bristol-Myers Squibb, diaDexus, GlaxoSmithKline, Kowa, Merck, Novartis, Roche, SanofiSynthelabo, Takeda, National Institutes of Health, American Diabetes Association, and American Heart Association; is a consultant for Abbott, Adnexus, Amylin, AstraZeneca, Bristol-Myers Squibb, Esperion, Genentech, GlaxoSmithKline, Idera Pharma, Kowa, Merck, Novartis, Omthera, Resverlogix, Roche, SanofiSynthelabo, and Takeda; serves on the speaker's bureau of Abbott, AstraZeneca, GlaxoSmithKline, and Merck; and has received honoraria from Abbott, AstraZeneca, GlaxoSmithKline, Merck, Sanofi-Synthelabo, and Takeda. EAS has received grant support (paid to institution, not individual) from AstraZeneca, Abbott, GlaxoSmithKline, Amarin, F Hoffmann-La Roche Inc, Sanofi-Aventis, Schering-Plough; serves on the speakers' bureau of AstraZeneca; is a consultant or served on advisory board for F Hoffmann-La Roche Inc, Sanofi-Aventis, and Schering-Plough. J-CT has received research grants and honoraria from Roche. JHFR has received honoraria from Roche and is part-supported by the National Institute for Health Research Cambridge Biomedical Research Centre. MEF has received honoraria from Roche. AT has received honoraria from Roche, BMS, and Novartis; and research grants from Merck, BMS, Genentech, GlaxoSmithKline, and VBL.

\section{Appendix}

\section{dal-PLAQUE Committees}

Executive Committee Z A Fayad (Chair), M E Farkouh, D Kallend (non-voting member), J

H F Rudd, A Tawakol, M Woodward (statistics).

Clinical Events Committee B Chaitman, R Bach, S Cruz-Flores, D Fintel, G Gosselin, C A

Sila, K Thygesen, G W Vetrovec.

Data Safety Monitoring Board B Buckley, G Steiner, A Ozonoff, H Hussein, B Lucey.

\section{dal-PLAQUE Investigators}

USA Christie M Ballantyne, Baylor College of Medicine, Houston; Timothy Bateman, Cardiovascular Imaging Technologies LLC, Kansas City; Daniel Duprez, University of Minnesota; Michael E Farkouh, Mount Sinai Medical Center, New York; Thomas

Hatsukami, University of Washington School of Medicine; Michael J Koren, Jacksonville Center for Clinical Research; James M Rhyne, Iredell Internal Medicine, Statesville; Eli

Roth, Sterling Research Group Ltd, Cinncinnati; Evan A Stein, Metabolic and Atherosclerosis Research Center, Cincinnati; Oliver Wong, William Beaumont Hospital Health Center, Michigan.

Canada Jean-Claude Tardif, Montreal Heart Institute.

\section{References}

1. Scandinavian Simvastatin Survival study group. Randomised trial of cholesterol lowering in 4444 patients with coronary heart disease: the Scandinavian Simvastatin Survival study (4S). Lancet. 1994; 344:1383-89. [PubMed: 7968073]

2. Cannon $\mathrm{CP}$, Braunwald $\mathrm{E}, \mathrm{McCabe} \mathrm{CH}$, et al. Intensive versus moderate lipid lowering with statins after acute coronary syndromes. N Engl J Med. 2004; 350:1495-04. [PubMed: 15007110] 
3. Baigent C, Blackwell L, Emberson J, et al. Cholesterol Treatment Trialists' (CTT) Collaboration. Efficacy and safety of more intensive lowering of LDL cholesterol: a meta-analysis of data from 170000 participants in 26 randomised trials. Lancet. 2010; 376:1670-81. [PubMed: 21067804]

4. Chapman MJ, Le Goff W, Guerin M, Kontush A. Cholesteryl ester transfer protein: at the heart of the action of lipid-modulating therapy with statins, fibrates, niacin, and cholesteryl ester transfer protein inhibitors. Eur Heart J. 2010; 31:149-64. [PubMed: 19825813]

5. Chapman MJ, Ginsberg HN, Amarenco P, et al. Triglyceride-rich lipoproteins and high-density lipoprotein cholesterol in patients at high risk of cardiovascular disease: evidence and guidance for management. Eur Heart J. 2011; 32:1345-61. [PubMed: 21531743]

6. Gordon T, Castelli WP, Hjortland MC, Kannel WB, Dawber TR. High density lipoprotein as a protective factor against coronary heart disease. The Framingham Study. Am J Med. 1977; 62:70714. [PubMed: 193398]

7. Boden WE. High-density lipoprotein cholesterol as an independent risk factor in cardiovascular disease: assessing the data from Framingham to the Veterans Affairs High-Density Lipoprotein Intervention Trial. Am J Cardiol. 2000; 86:19L-22L.

8. Jafri H, Alsheikh-Ali AA, Karas RH. Meta-analysis: statin therapy does not alter the association between low levels of high-density lipoprotein cholesterol and increased cardiovascular risk. Ann Intern Med. 2010; 153:800-08. [PubMed: 21173414]

9. Arsenault BJ, Barter P, DeMicco DA, et al. Prediction of cardiovascular events in statin-treated stable coronary patients by lipid and nonlipid biomarkers. J Am Coll Cardiol. 2011; 57:63-69. [PubMed: 21185503]

10. Johnsen SH, Mathiesen EB, Fosse E, et al. Elevated high-density lipoprotein cholesterol levels are protective against plaque progression: a follow-up study of 1952 persons with carotid atherosclerosis the Troms $\varnothing$ study. Circulation. 2005; 112:498-504. [PubMed: 16027250]

11. Wei L, Murphy MJ, MacDonald TM. Impact on cardiovascular events of increasing high density lipoprotein cholesterol with and without lipid lowering drugs. Heart. 2006; 92:746-51. [PubMed: 16216856]

12. Barter PJ, Caulfield M, Eriksson M, et al. Effects of torcetrapib in patients at high risk for coronary events. N Engl J Med. 2007; 357:2109-122. [PubMed: 17984165]

13. Rader DJ. Illuminating HDL—is it still a viable therapeutic target? N Engl J Med. 2007; 357:2180-83. [PubMed: 17984168]

14. Niesor EJ, Magg C, Ogawa N, et al. Modulating cholesterol ester transfer protein activity maintains efficient pre- $\beta$-HDL formation and increases reverse cholesterol transport. J Lipid Res. 2010; 51:3443-54. [PubMed: 20861162]

15. Stein EA, Stroes ESG, Steiner G, et al. Safety and tolerability of dalcetrapib. Am J Cardiol. 2009; 104:82-91. [PubMed: 19576325]

16. Stein EA, Roth EM, Rhyne JM, Burgess T, Kallend D, Robinson JG. Safety and tolerability of dalcetrapib (RO4607381/ JTT-705): results from a 48-week trial. Eur Heart J. 2010; 31:480-88. [PubMed: 20097702]

17. Stroes ESG, Kastelein JJP, Benardeau A, et al. Dalcetrapib: no off-target toxicity on blood pressure or on genes related to the rennin angiotensin-aldosterone system in rats. Br J Pharmacol. 2009; 158:1763-70. [PubMed: 19917065]

18. Okamoto H, Yonemori F, Wakitani K, Minowa T, Maeda K, Shinkai H. A cholesteryl ester transfer protein inhibitor attenuates atherosclerosis in rabbits. Nature. 2000; 406:203-07. [PubMed: 10910363]

19. Mani V, Itskovich VV, Szimtenings M, et al. Rapid extended coverage simultaneous multisection black-blood vessel wall MR imaging. Radiology. 2004; 232:281-88. [PubMed: 15220509]

20. Rudd JH, Myers KS, Bansilal S, et al. (18) Fluorodeoxyglucose positron emission tomography imaging of atherosclerotic plaque inflammation is highly reproducible: implications for atherosclerosis therapy trials. J Am Coll Cardiol. 2007; 50:892-96. [PubMed: 17719477]

21. Mani V, Muntner P, Gidding SS, et al. Cardiovascular magnetic resonance parameters of atherosclerotic plaque burden improve discrimination of prior major adverse cardiovascular events. J Cardiovasc Magn Reson. 2009; 11:10. [PubMed: 19393089] 
22. Rudd JH, Narula J, Strauss HW, et al. Imaging atherosclerotic plaque inflammation by fluorodeoxyglucose with positron emission tomography: ready for prime time? J Am Coll Cardiol. 2010; 55:2527-35. [PubMed: 20513592]

23. Naghavi M, Falk E, Hecht HS, et al. SHAPE Task Force. From vulnerable plaque to vulnerable patient-Part III: Executive summary of the Screening for Heart Attack Prevention and Education (SHAPE) Task Force report. Am J Cardiol. 2006; 98:2H-15H.

24. Shah PK. Screening asymptomatic subjects for subclinical atherosclerosis: can we, does it matter, and should we? J Am Coll Cardiol. 2010; 56:98-105. [PubMed: 20620724]

25. Tardif JC, Lesage F, Harel F, Romeo P, Pressacco J. Imaging biomarkers in atherosclerosis trials. Circ Cardiovasc Imaging. 2011; 4:319-33. [PubMed: 21586743]

26. Fayad ZA, Mani V, Woodward M, et al. Rationale and design of dal-PLAQUE: a study assessing efficacy and safety of dalcetrapib on progression or regression of atherosclerosis using magnetic resonance imaging and $18 \mathrm{~F}$-fluorodeoxyglucose positron emission tomography/computed tomography. Am Heart J. 2011; 162:214-21. [PubMed: 21835280]

27. Grundy SM, Cleeman JI, Merz CNB, et al. Implications of recent clinical trials for the national cholesterol education program adult treatment panel III guidelines. Circulation. 2004; 110:227-39. [PubMed: 15249516]

28. Tawakol A, Migrino RQ, Bashian GG, et al. In vivo 18F-fluorodeoxyglucose positron emission tomography imaging provides a noninvasive measure of carotid plaque inflammation in patients. J Am Coll Cardiol. 2006; 48:1818-24. [PubMed: 17084256]

29. Mani V, Itskovich VV, Aguiar SH, et al. Comparison of gated and non-gated fast multislice blackblood carotid imaging using rapid extended coverage and inflow/outflow saturation techniques. $\mathrm{J}$ Magn Reson Imaging. 2005; 22:628-33. [PubMed: 16215965]

30. Hayashi K, Mani V, Nemade A, et al. Variations in atherosclerosis and remodeling patterns in aorta and carotids. J Cardiovasc Magn Reson. 2010; 12:10. [PubMed: 20205722]

31. Rudd JH, Myers KS, Bansilal S, et al. Atherosclerosis inflammation imaging with 18F-FDG PET: carotid, iliac, and femoral uptake reproducibility, quantification methods, and recommendations. J Nucl Med. 2008; 49:871-78. [PubMed: 18483100]

32. El Aidi H, Mani V, Weinshelbaum KB, et al. Cross-sectional, prospective study of MRI reproducibility in the assessment of plaque burden of the carotid arteries and aorta. Nat Clin Pract Cardiovasc Med. 2009; 6:219-28. [PubMed: 19174763]

33. Tahara N, Kai H, Ishibashi M, et al. Simvastatin attenuates plaque inflammation-evaluation by fluorodeoxyglucose positron emission tomography. J Am Coll Cardiol. 2006; 48:1825-31. [PubMed: 17084257]

34. Rye KA, Bursill CA, Lambert G, Tabet F, Barter PJ. The metabolism and anti-atherogenic properties of HDL. J Lipid Res. 2009; 50:S195-200. [PubMed: 19033213]

35. Nissen SE, Tsunoda T, Tuzcu EM, et al. Effect of recombinant ApoA-I Milano on coronary atherosclerosis in patients with acute coronary syndromes: a randomized controlled trial. JAMA. 2003; 290:2292-300. [PubMed: 14600188]

36. Hirano K, Yamashita S, Kuga Y, et al. Atherosclerotic disease in marked hyperalphalipoproteinemia. Combined reduction of cholesteryl ester transfer protein and hepatic triglyceride lipase. Arterioscler Thromb Vasc Biol. 1995; 15:1849-56. [PubMed: 7583564]

37. Zhong S, Sharp DS, Grove JS, et al. Increased coronary heart disease in Japanese-American men with mutation in the cholesteryl ester transfer protein gene despite increased HDL levels. J Clin Invest. 1996; 97:2917-23. [PubMed: 8675707]

38. Curb JD, Abbott RD, Rodriguez BL, et al. A prospective study of HDL-C and cholesteryl ester transfer protein gene mutations and the risk of coronary heart disease in the elderly. J Lipid Res. 2004; 45:948-53. [PubMed: 14967821]

39. Boekholdt SM, Sacks FM, Jukema JW, et al. Cholesteryl ester transfer protein TaqIB variant, highdensity lipoprotein cholesterol levels, cardiovascular risk, and efficacy of pravastatin treatment: individual patient meta-analysis of 13,677 subjects. Circulation. 2005; 111:278-87. [PubMed: 15655129]

40. Barter PJ, Kastelein JJ. Targeting cholesteryl ester transfer protein for the prevention and management of cardiovascular disease. J Am Coll Cardiol. 2006; 47:492-99. [PubMed: 16458126] 
41. Vasan RS, Pencina MJ, Robins SJ, et al. Association of circulating cholesteryl ester transfer protein activity with incidence of cardiovascular disease in the community. Circulation. 2009; 120:2414-20. [PubMed: 19948972]

42. Robinson JG. Dalcetrapib: a review of Phase II data. Expert Opin Investig Drugs. 2010; 19:795805.

43. Rudd JH, Warburton EA, Fryer TD, et al. Imaging atherosclerotic plaque inflammation with [18F]fluorodeoxyglucose positron emission tomography. Circulation. 2002; 105:2708-11. [PubMed: 12057982]

44. Paulmier B, Duet M, Khayat R, et al. Arterial wall uptake of fluorodeoxyglucose on PET imaging in stable cancer disease patients indicates higher risk for cardiovascular events. J Nucl Cardiol. 2008; 15:209-17. [PubMed: 18371592]

45. Lee SJ, On YK, Lee EJ, Choi JY, Kim BT, Lee KH. Reversal of vascular 18F-FDG uptake with plasma high-density lipoprotein elevation by atherogenic risk reduction. J Nucl Med. 2008; 49:1277-82. [PubMed: 18632820]

46. Duivenvoorden R, de Groot E, Elsen BM, et al. In vivo quantification of carotid artery wall dimensions: 3.0-Tesla MRI versus B-mode ultrasound imaging. Circ Cardiovasc Imaging. 2009; 2:235-42. [PubMed: 19808598]

47. Mani V, Aguiar SH, Itskovich VV, et al. Carotid black blood MRI burden of atherosclerotic disease assessment correlates with ultrasound intima-media thickness. J Cardiovasc Magn Reson. 2006; 8:529-34. [PubMed: 16755842]

48. Glagov S, Weisenberg E, Zarins CK, Stankunavicius R, Kolettis GJ. Compensatory enlargement of human atherosclerotic coronary arteries. N Engl J Med. 1987; 316:1371-75. [PubMed: 3574413]

49. Schoenhagen P, Ziada KM, Kapadia SR, Crowe TD, Nissen SE, Tuzcu EM. Extent and direction of arterial remodeling in stable $v s$ unstable coronary syndromes : an intravascular ultrasound study. Circulation. 2000; 101:598-603. [PubMed: 10673250]

50. Nissen SE, Tuzcu EM, Brown BG, et al. Effect of intensive compared with moderate lipidlowering therapy on progression of coronary atherosclerosis: a randomized controlled trial. JAMA. 2004; 291:1071-80. [PubMed: 14996776]

51. Nissen SE, Tuzcu EM, Libby P, et al. Effect of antihypertensive agents on cardiovascular events in patients with coronary disease and normal blood pressure: the CAMELOT study: a randomized controlled trial. JAMA. 2004; 292:2217-26. [PubMed: 15536108]

52. Tardif JC, Gregoire J, L'Allier PL, et al. Avasimibe and Progression of Lesions on Ultrasound (APLUS) Investigators. Effects of the acyl coenzyme A: cholesterol acyltransferase inhibitor avasimibe on human atherosclerotic lesions. Circulation. 2004; 110:3372-77. [PubMed: 15533865]

53. Nissen SE, Nicholls SJ, Sipahi I, et al. Effect of very high-intensity statin therapy on regression of coronary atherosclerosis: the ASTEROID trial. JAMA. 2006; 295:1556-65. [PubMed: 16533939]

54. Pasterkamp G, Schoneveld AH, van Wolferen W, et al. The impact of atherosclerotic arterial remodeling on percentage of luminal stenosis varies widely within the arterial system. A postmortem study. Arterioscler Thromb Vasc Biol. 1997; 17:3057-63. [PubMed: 9409293]

55. Corti R, Fayad ZA, Fuster V, et al. Effects of lipid-lowering by simvastatin on human atherosclerotic lesions: a longitudinal study by high-resolution, noninvasive magnetic resonance imaging. Circulation. 2001; 104:249-52. [PubMed: 11457739]

56. Corti R, Fuster V, Fayad ZA, et al. Lipid lowering by simvastatin induces regression of human atherosclerotic lesions: two years' follow-up by high-resolution noninvasive magnetic resonance imaging. Circulation. 2002; 106:2884-87. [PubMed: 12460866]

57. Underhill HR, Yuan C, Zhao XQ, et al. Effect of rosuvastatin therapy on carotid plaque morphology and composition in moderately hypercholesterolemic patients: a high-resolution magnetic resonance imaging trial. Am Heart J. 2008; 155:584.e1-8. [PubMed: 18294500]

58. Rudd JH, Myers KS, Bansilal S, et al. Relationships among regional arterial inflammation, calcification, risk factors, and biomarkers: a prospective fluorodeoxyglucose positron-emission tomography/ computed tomography imaging study. Circ Cardiovasc Imaging. 2009; 2:107-15. [PubMed: 19808576] 
59. Tahara N, Kai H, Yamagishi S, et al. Vascular inflammation evaluated by [18F]fluorodeoxyglucose positron emission tomography is associated with the metabolic syndrome. $\mathrm{J}$ Am Coll Cardiol. 2007; 49:1533-39. [PubMed: 17418291]

60. Kastelein JJ, Duivenvoorden R, Deanfield J, et al. Rationale and design of dal-VESSEL: a study to assess the safety and efficacy of dalcetrapib on endothelial function using brachial artery flowmediated vasodilatation. Curr Med Res Opin. 2011; 27:141-50. [PubMed: 21128879]

61. Tellis CC, Tselepis AD. The role of lipoprotein-associated phospholipase A2 inatherosclerosis may depend on its lipoprotein carrier in plasma. Biochim Biophys Acta. 2009; 1791:327-38. [PubMed: 19272461]

62. Corsetti JP, Ryan D, Rainwater DL, Moss AJ, Zareba W, Sparks CE. Cholesteryl ester transfer protein polymorphism (TaqIB) associates with risk in postinfarction patients with high C-reactive protein and high-density lipoprotein cholesterol levels. Arterioscler Thromb Vasc Biol. 2010; 30:1657-64. [PubMed: 20489166]

63. Martín-Ventura JL, Blanco-Colio LM, Gómez-Hernández A, et al. Intensive treatment with atorvastatin reduces inflammation in mononuclear cells and human atherosclerotic lesions in one month. Stroke. 2005; 36:1796-800. [PubMed: 16020773]

64. Schwartz GG, Olsson AG, Ballantyne CM, et al. Rationale and design of the dal-OUTCOMES trial: efficacy and safety of dalcetrapib in patients with recent acute coronary syndrome. Am Heart J. 2009; 158:896-901. e3. [PubMed: 19958854] 


\section{Panel: Research in context}

\section{Systematic review}

We did a search in PubMed, using the search terms "atherosclerosis", "HDL", and "imaging”, for studies published between 1980 and 2011. As PET and MRI are new techniques for vascular imaging, there are no available meta-analyses on this topic. The results of the present study are analysed in context with previous findings, incorporating discussion on the pro-atherogenicity or anti-atherogenicity of CETP activity and examining the findings of other imaging trials of cardiovascular therapies. We also include reference to the review on imaging biomarkers in atherosclerosis trials by Tardif and colleagues. ${ }^{25}$

\section{Interpretation}

The present study, dal-PLAQUE, was the longest placebo-controlled active-drug MRI study so far and the first to use non-invasive multimodality imaging (including PET) as primary endpoints. The imaging techniques were used to identify the effects of dalcetrapib on vascular endpoints and overall, the trial showed no evidence of a pathological effect. Confirmation of the long-term safety and efficacy of dalcetrapib will be assessed in the ongoing dal-OUTCOMES study. 


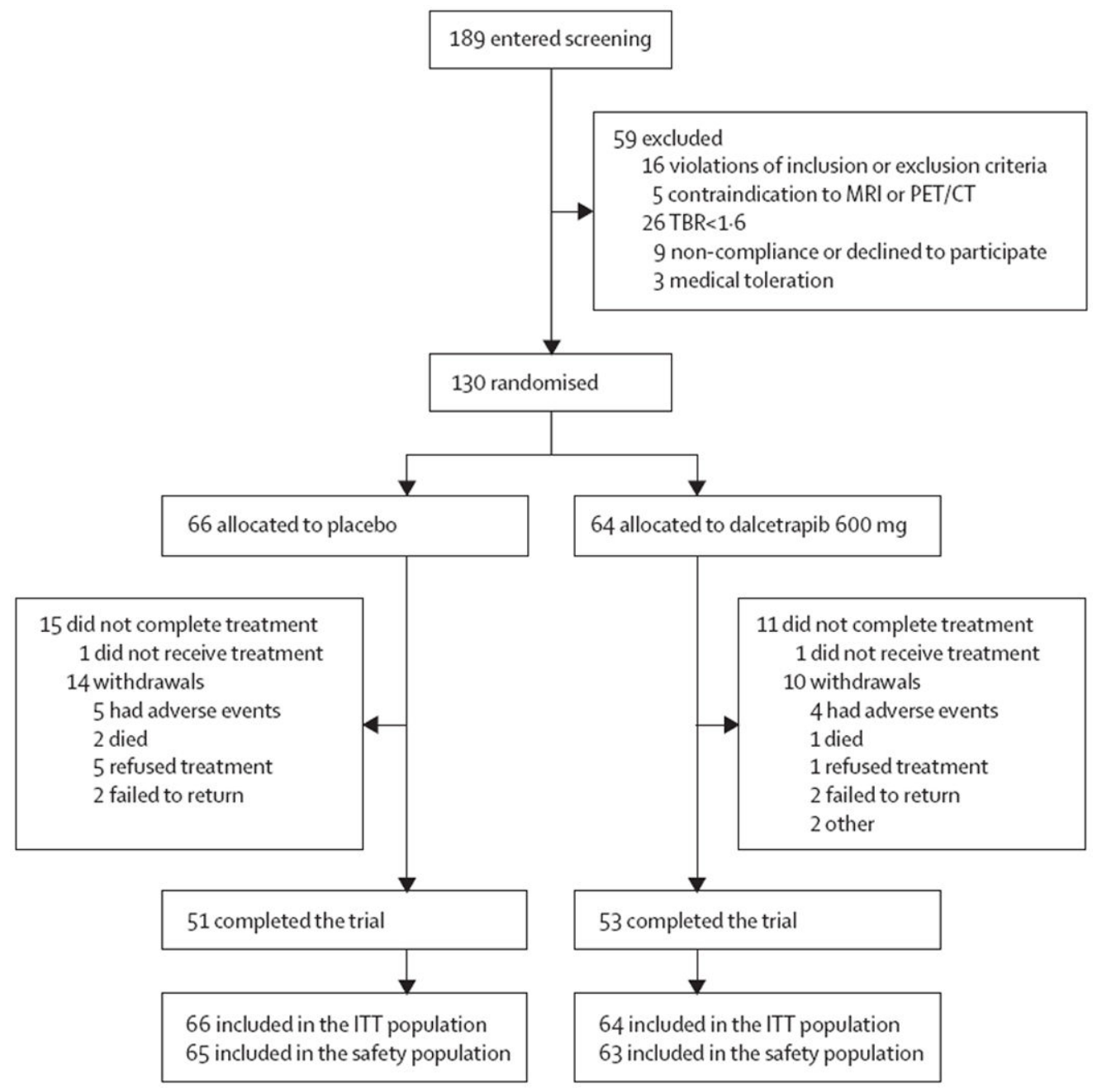

Figure 1. Trial profile 


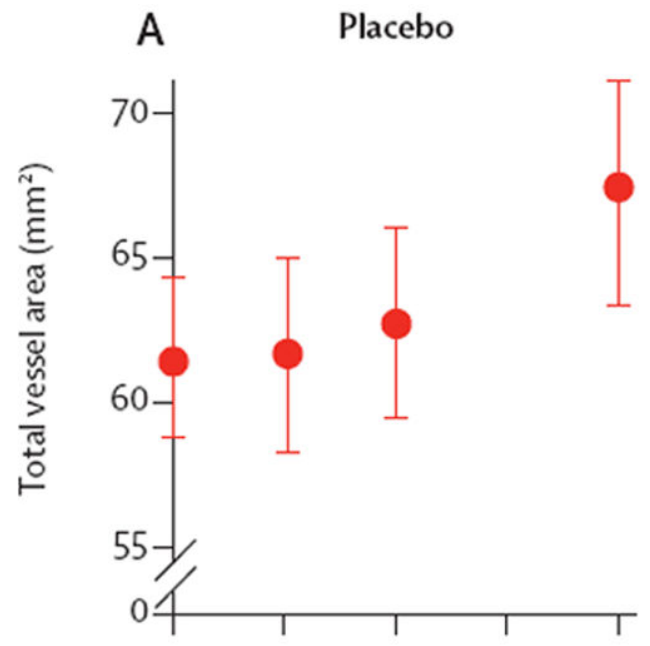

Dalcetrapib
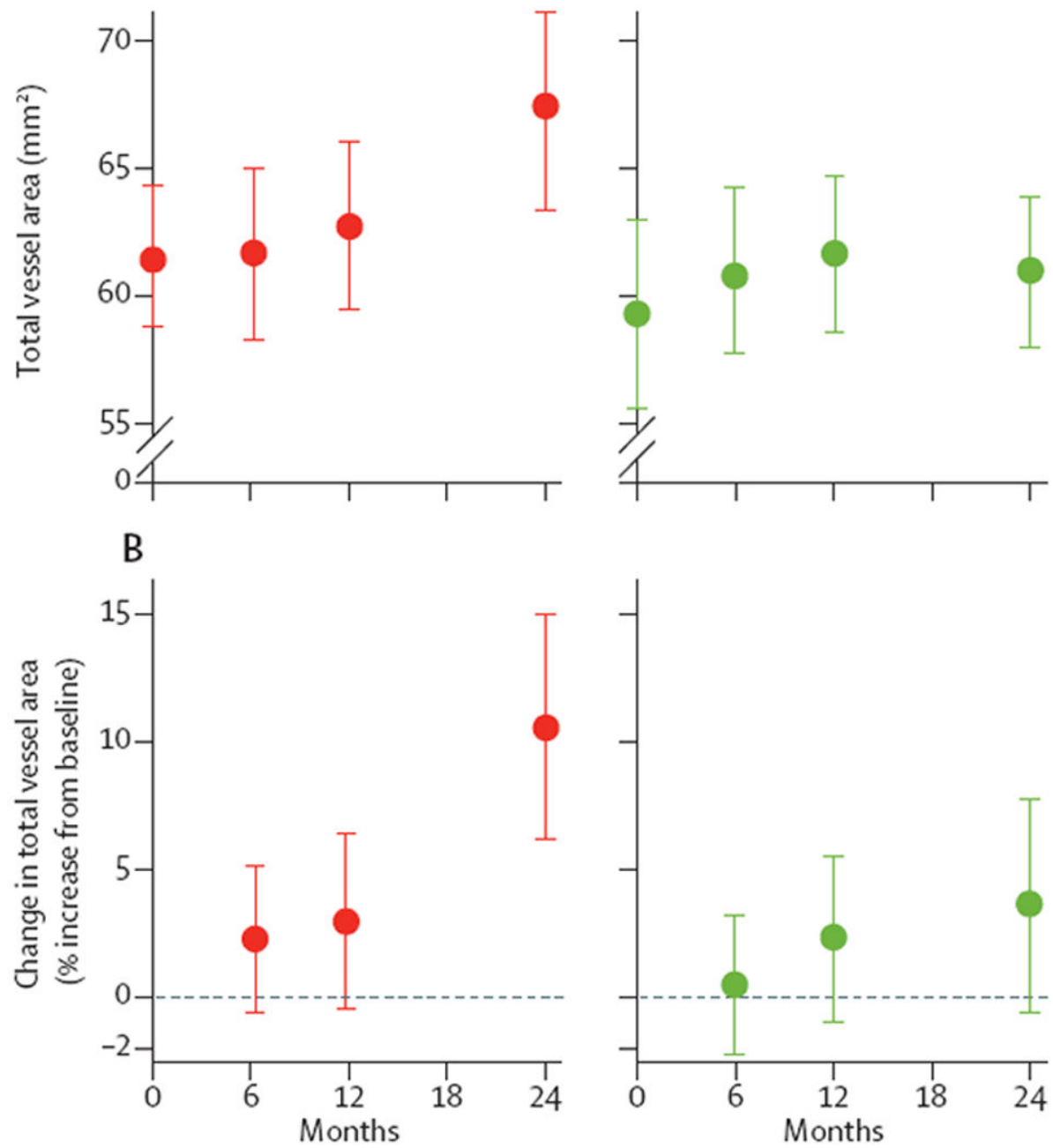

Figure 2. Mean carotid total vessel area and percent increase in average carotid total vessel area (by MRI)

(A) Raw mean data (90\% CI) for total vessel area at baseline, 6, 12, and 24 months. Total vessel area increased after 24 months in the placebo group: model-derived, corrected average absolute change (24 months-baseline) was $5 \cdot 72 \mathrm{~mm}^{2}$ (90\% CI 3.30-8.14), $\mathrm{p}=0 \cdot 0002$. However, in the dalcetrapib group, total vessel area did not change in the same period $(1 \cdot 71$ [ -0.68 to $4 \cdot 10], \mathrm{p}=0 \cdot 24)$. The average reduction in total vessel area on dalcetrapib (versus placebo), after correction of baseline, was $-4 \cdot 01(-7 \cdot 23$ to $-0 \cdot 80)$, $\mathrm{p}=0 \cdot 04$. (B) Group mean data for percent change in total vessel area at 6, 12, and 24 months (relative to baseline). In patients assigned placebo, model-derived, corrected total vessel area increased in the initial 24 months: percent change total vessel area was $10 \cdot 8$ (90\% CI 5.8$15 \cdot 8), \mathrm{p}=0 \cdot 001$. However, in patients assigned dalcetrapib, total vessel area did not increase in the same period $(4.0 \%[0.6-7 \cdot 3], \mathrm{p}=0 \cdot 16)$. The average percent change in total vessel area in the dalcetrapib group (versus placebo), after correction of baseline, was $-7 \cdot 1 \%(-12 \cdot 8$ to $-1 \cdot 3), \mathrm{p}=0 \cdot 04$. 


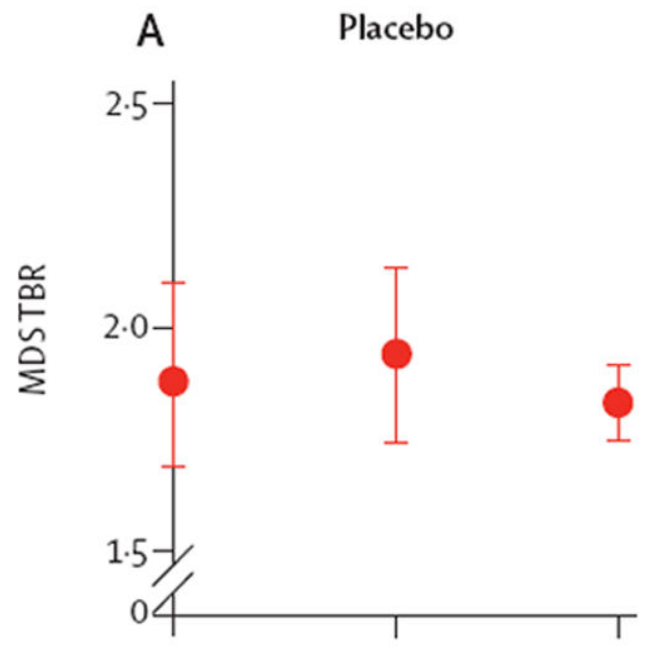

Dalcetrapib
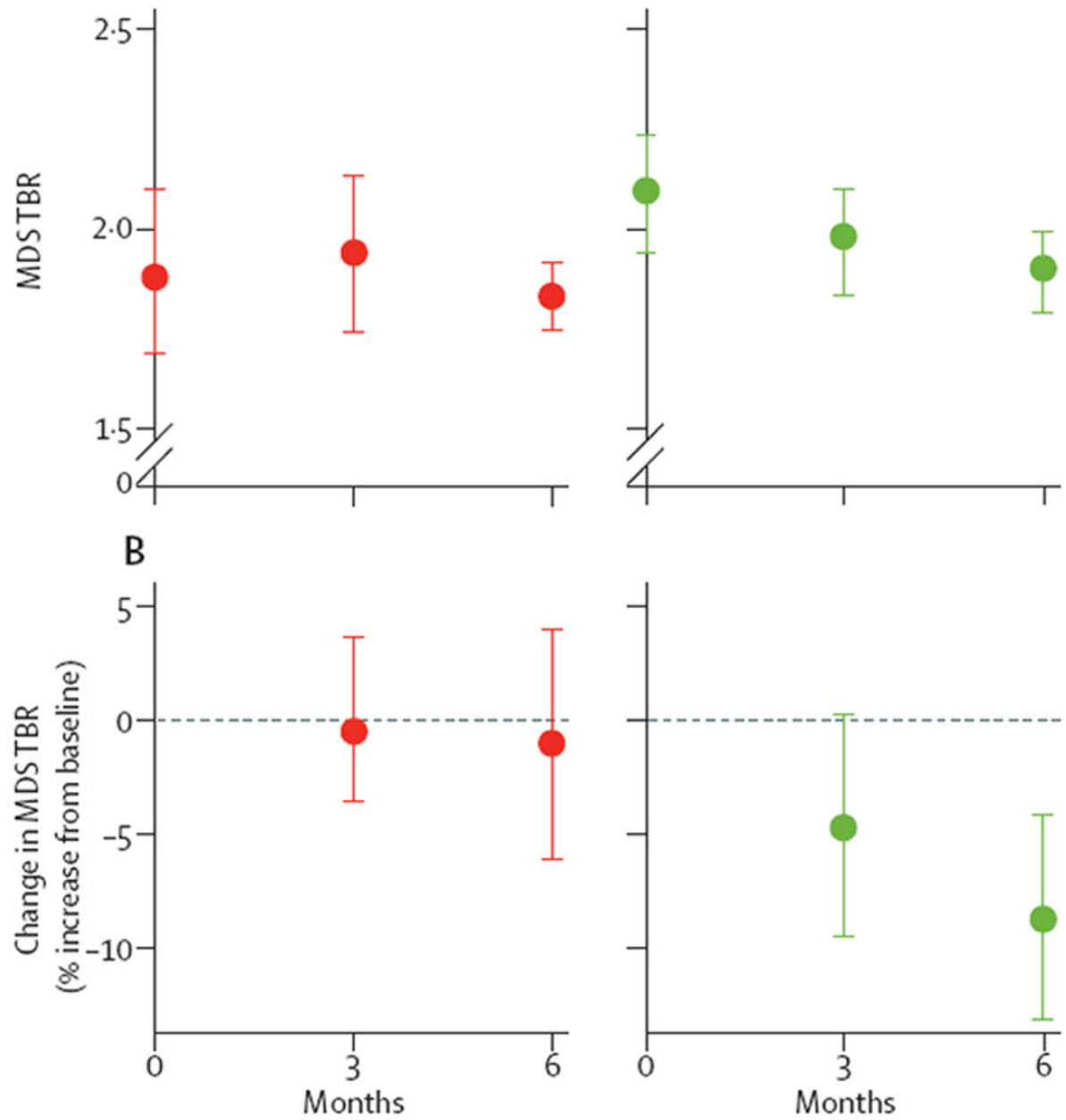

Figure 3. Mean carotid MDS TBR and percent increase in average carotid most-diseasedsegment TBR (by PET)

MDS=most-diseased-segment. TBR=target-to-background ratio. (A) Raw mean data for average carotid MDS TBR at baseline, and at 3 and 6 months. In the placebo group, MDS TBR did not change after 6 months: model-derived, corrected average absolute change for MDS TBR (6 months-baseline) was -0.043 (90\% CI $-0 \cdot 14$ to $0 \cdot 06$ ), $\mathrm{p}=0 \cdot 48$. However, in the dalcetrapib group, MDS TBR decreased in the same period ( $-0 \cdot 19$ [ $-0 \cdot 29$ to $-0 \cdot 09]$, $\mathrm{p}=0.001$ ). The average reduction in MDS TBR on dalcetrapib (versus placebo), after correction for baseline, was $-0 \cdot 150(-0.29$ to -0.01$), p=0 \cdot 08$. (B) Group mean (90\% CI) data for percent change in average carotid MDS TBR after 3 and 6 months (relative to baseline). In the placebo group, model-derived, corrected average MDS TBR did not change over the initial 6 months: percent change in MDS TBR was 3.24 (90\% CI -2.18 to 8.66), p=0.71. However, in the dalcetrapib group, MDS TBR decreased in the same period $(-7 \cdot 26 \%$ [ -12.50 to $-2 \cdot 02], \mathrm{p}=0.003)$. The estimated average percent change in MDS TBR on dalcetrapib (versus placebo), after correction for baseline, was $-7 \cdot 35 \%$ (90\% CI -13.49 to $-0 \cdot 76), \mathrm{p}=0 \cdot 07$. 

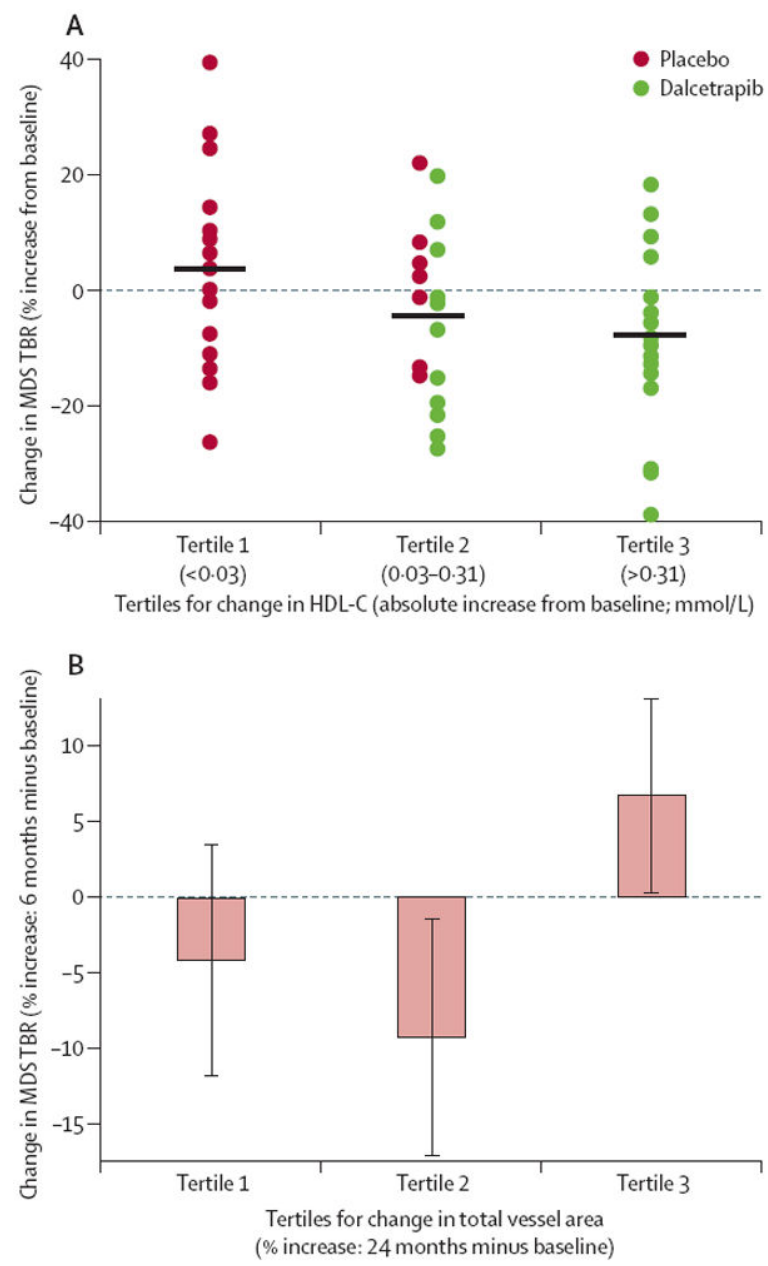

Figure 4.

Association between HDL-C and arterial inflammation as measured by MDS TBR on PET/CT and arterial inflammation and atherosclerotic burden HDL-C=high-density lipoprotein cholesterol. MDS=most-diseased-segment. TBR=target-to-background ratio. (A) Change in arterial inflammation (MDS TBR) over 6 months versus change in HDL-C over the same period grouped in tertiles (third tertile represents the greatest increase in HDL-C). (B) Early increases in arterial inflammation associated with subsequent increases in atherosclerotic burden. The change in carotid inflammation at 6 months was compared within subjects that were classified into tertiles according to the subsequent rate of change in total vessel area at 24 months. 
Table 1

Baseline demographic and clinical characteristics

\begin{tabular}{|c|c|c|}
\hline & Placebo $(n=66)$ & Dalcetrapib $(n=64)$ \\
\hline Age, years & $64 \cdot 6(7 \cdot 8)$ & $62 \cdot 6(8 \cdot 2)$ \\
\hline Male sex & $55(83 \%)$ & $51(80 \%)$ \\
\hline Body-mass index $\left(\mathrm{kg} / \mathrm{m}^{2}\right)$ & $29 \cdot 8(6 \cdot 2)$ & $29 \cdot 6(4 \cdot 8)$ \\
\hline White race* & $62(94 \%)$ & $58(91 \%)$ \\
\hline \multicolumn{3}{|l|}{ Medical history of } \\
\hline Coronary heart disease & $54(82 \%)$ & $57(89 \%)$ \\
\hline Symptomatic coronary artery disease & $5(8 \%)$ & $5(8 \%)$ \\
\hline Hypertension & $48(73 \%)$ & $47(73 \%)$ \\
\hline Type 2 diabetes & $20(30 \%)$ & $19(30 \%)$ \\
\hline Abdominal aortic aneurysm & $2(3 \%)$ & $3(5 \%)$ \\
\hline Peripheral arterial disease & $10(15 \%)$ & $6(9 \%)$ \\
\hline Present smoker & $8(12 \%)$ & $9(14 \%)$ \\
\hline High sensitivity C-reactive protein, mg/L(median, IQR) & $1 \cdot 4(0 \cdot 8-2 \cdot 8)$ & $1.4(0 \cdot 6-3 \cdot 7)$ \\
\hline Statin use & $61(92 \%)$ & $52(81 \%)$ \\
\hline Apolipoprotein B (g/L) & $0 \cdot 8(0 \cdot 2)$ & $0 \cdot 8(0 \cdot 2)$ \\
\hline Apolipoprotein A1 (g/L) & $1 \cdot 4(0 \cdot 3)$ & $1 \cdot 4(0 \cdot 2)$ \\
\hline \multicolumn{3}{|l|}{ Plasma lipid profile } \\
\hline Total cholesterol, $\mathrm{mmol} / \mathrm{L}$ & $3 \cdot 8(0 \cdot 7)$ & $3 \cdot 7(0 \cdot 7)$ \\
\hline $\mathrm{HDL}-\mathrm{C}, \mathrm{mmol} / \mathrm{L}$ & $1 \cdot 2(0 \cdot 4)$ & $1 \cdot 1(0 \cdot 3)$ \\
\hline $\mathrm{LDL}-\mathrm{C}, \mathrm{mmol} / \mathrm{L}$ & $1.9(0.5)$ & $1 \cdot 9(0 \cdot 6)$ \\
\hline Triglycerides, mmol/L (median, IQR) & $1.5(1 \cdot 0-1 \cdot 8)$ & $1.4(1.0-1.9)$ \\
\hline \multicolumn{3}{|l|}{ MRI (average carotid) ${ }^{\dagger}$} \\
\hline Total vessel area, $\mathrm{mm}^{2}$ & $60 \cdot 2(12 \cdot 9)$ & $62 \cdot 8(17 \cdot 8)$ \\
\hline Wall area, $\mathrm{mm}^{2}$ & $29.5(8 \cdot 9)$ & $30 \cdot 0(9 \cdot 3)$ \\
\hline Wall thickness, mm & $1.23(0.29)$ & $1 \cdot 21(0 \cdot 22)$ \\
\hline Normalised wall index, $\%$ & $48 \cdot 1(6 \cdot 91)$ & $47 \cdot 1(5.93)$ \\
\hline \multicolumn{3}{|l|}{$\mathrm{PET} / \mathrm{CT}$ index vessel ${ }^{\ddagger}$} \\
\hline Aorta & $47(84 \%)$ & $50(88 \%)$ \\
\hline Left carotid & $6(11 \%)$ & 0 \\
\hline Right carotid & $3(5 \%)$ & $7(12 \%)$ \\
\hline \multicolumn{3}{|l|}{ PET/CT target-to-background ratio $\S$} \\
\hline Most diseased segment mean of maximum & $2 \cdot 8(0 \cdot 7)$ & $2 \cdot 7(0 \cdot 7)$ \\
\hline
\end{tabular}




\begin{tabular}{|lcc|}
\hline & Placebo $(\mathbf{n}=\mathbf{6 6})$ & Dalcetrapib $(\mathbf{n}=\mathbf{6 4})$ \\
\hline Mean of maximum & $2.6(0.6)$ & $2.5(0.6)$ \\
Mean of mean & $1.9(0.3)$ & $1.8(0.4)$ \\
\hline
\end{tabular}

Data are $\mathrm{n}(\%)$ or mean (SD) unless otherwise stated. IQR=interquartle range. HDL-C=high-density lipoprotein-cholesterol. LDL-C=low-density lipoprotein-cholesterol.

* Race or ethnic group was determined by the investigators.

${ }^{\dagger}$ Total number of patients with MRI vessel parameter measurements was 56 for placebo and 58 for dalcetrapib. Includes all patients with measurements available.

${ }^{*}$ Total number of patients with PET/CT data was 56 for placebo and 57 for dalcetrapib.

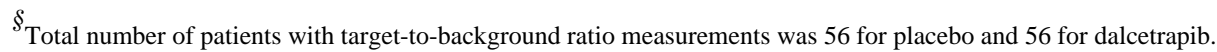




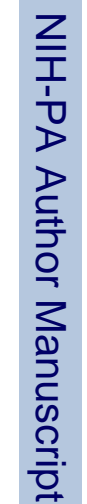

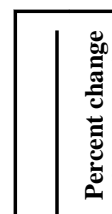

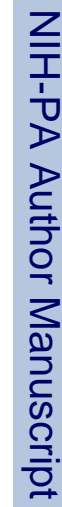

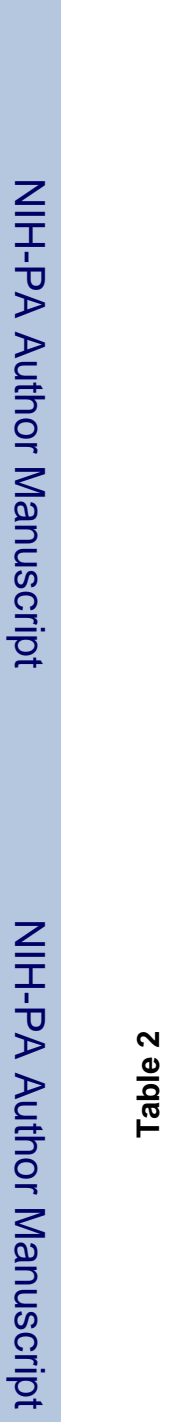

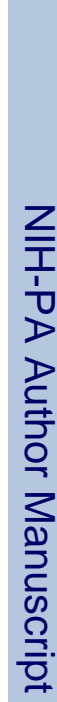

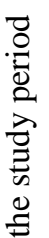

产

言

㝵

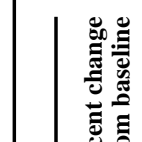

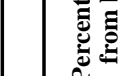

:

(ะ)

音

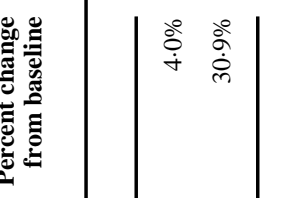

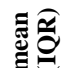

$+$

泀产

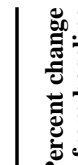

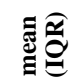

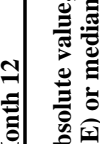

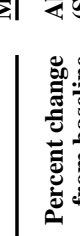

㮫

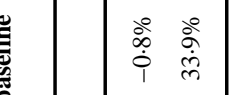

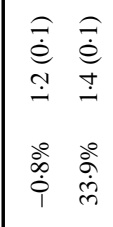

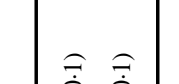

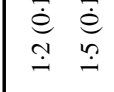

ڤั)

i ले

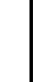

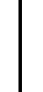

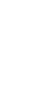

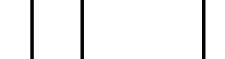

究 ஃ。

$\stackrel{\infty}{i}$

- 10 


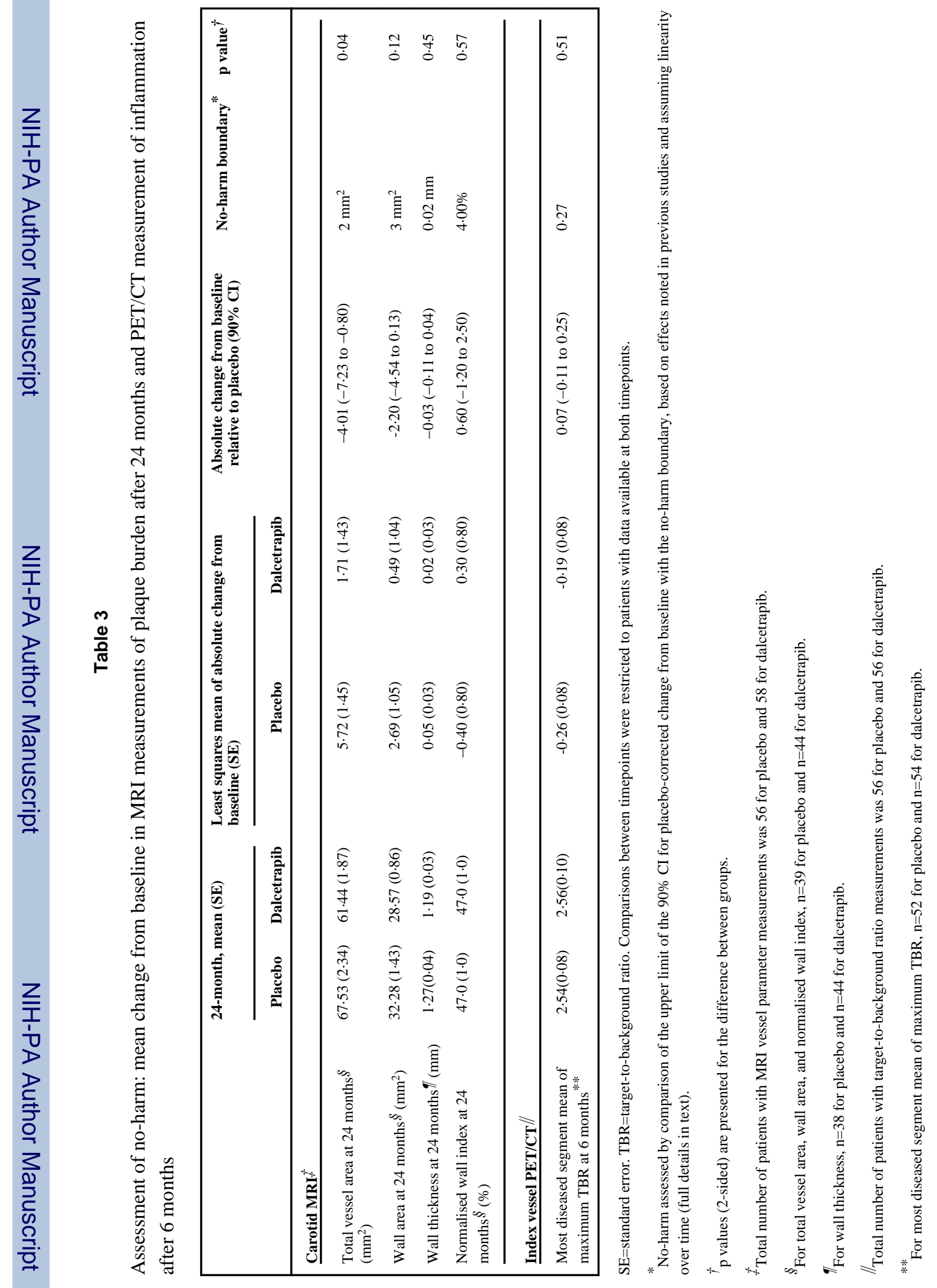




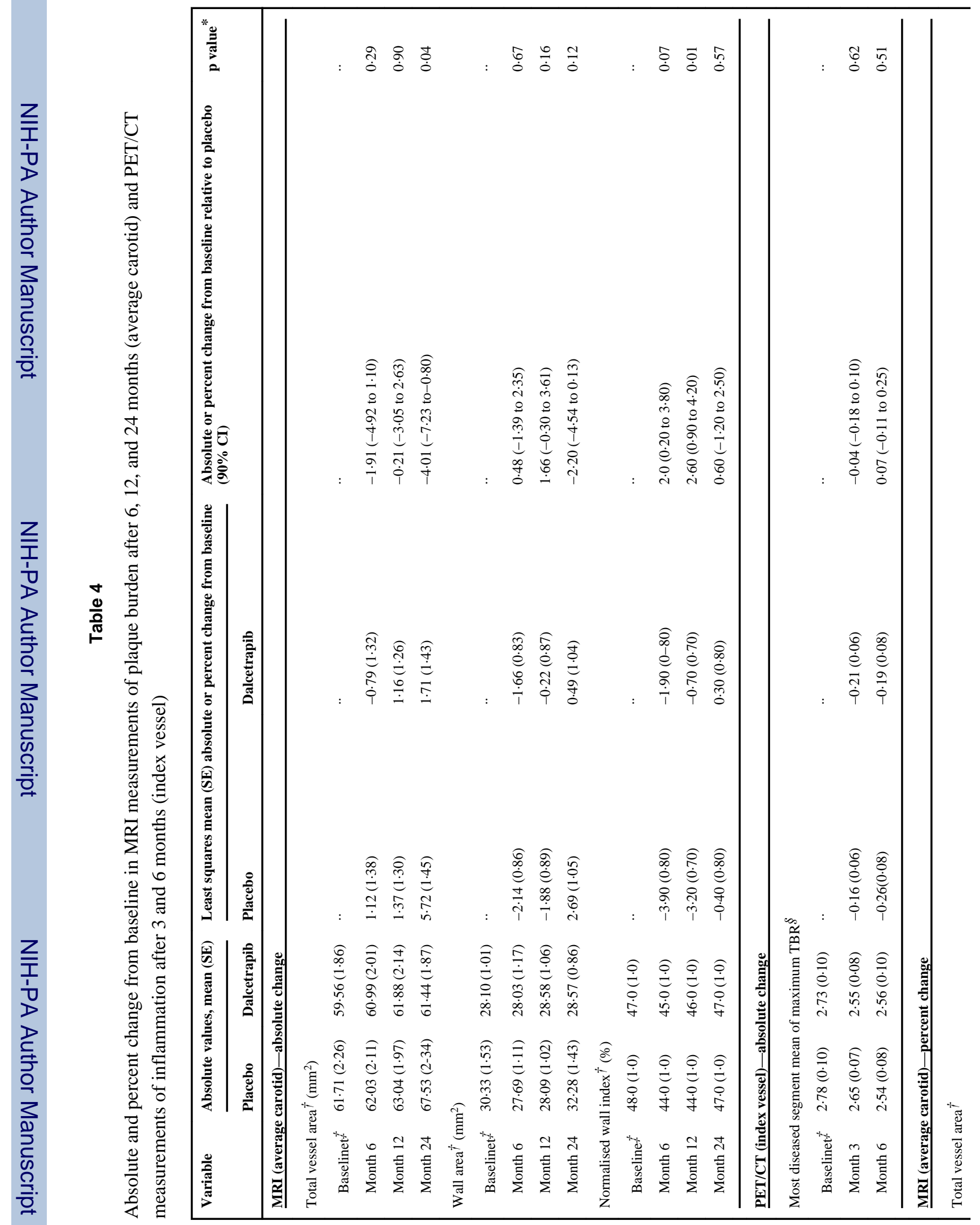




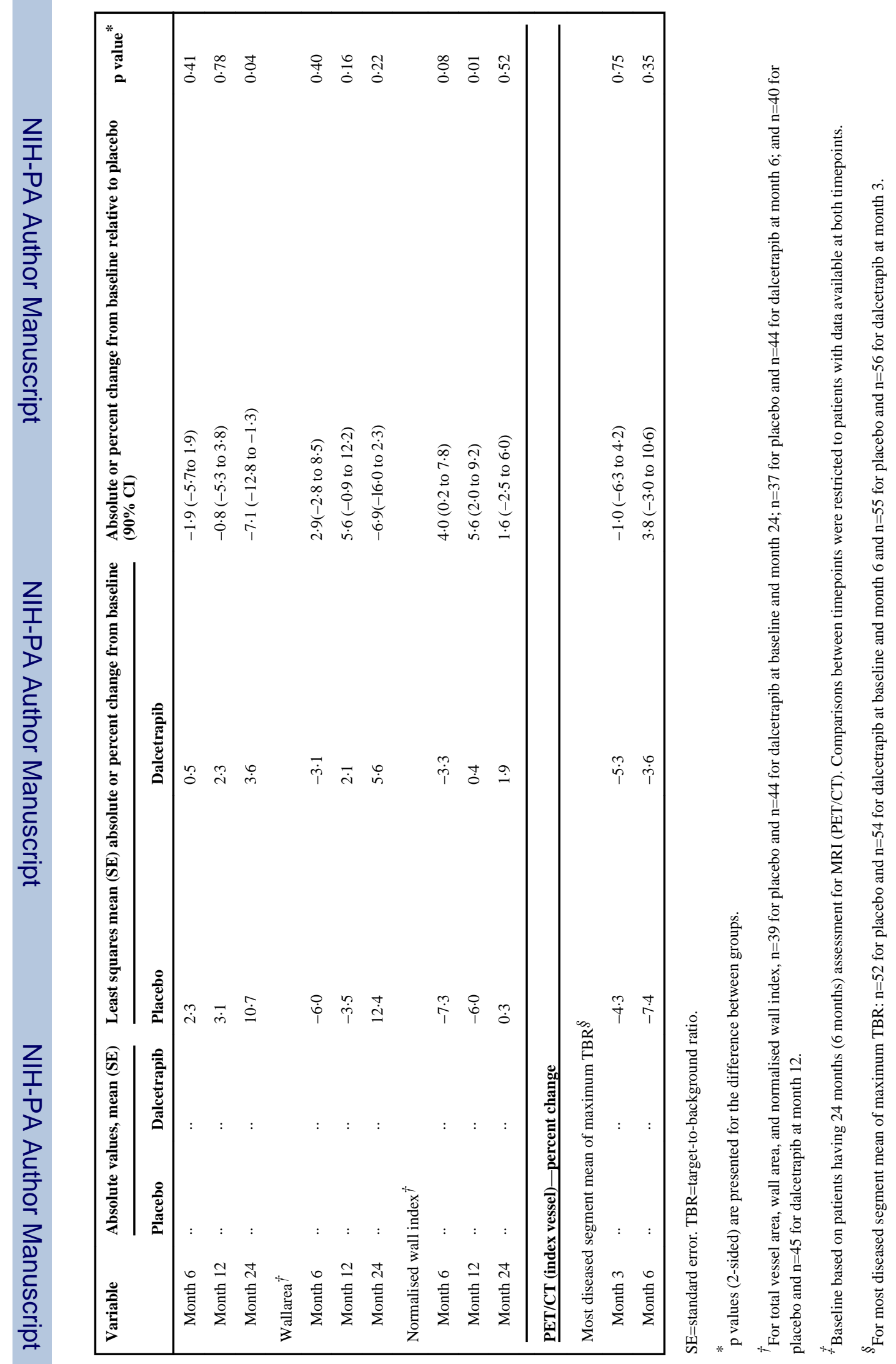




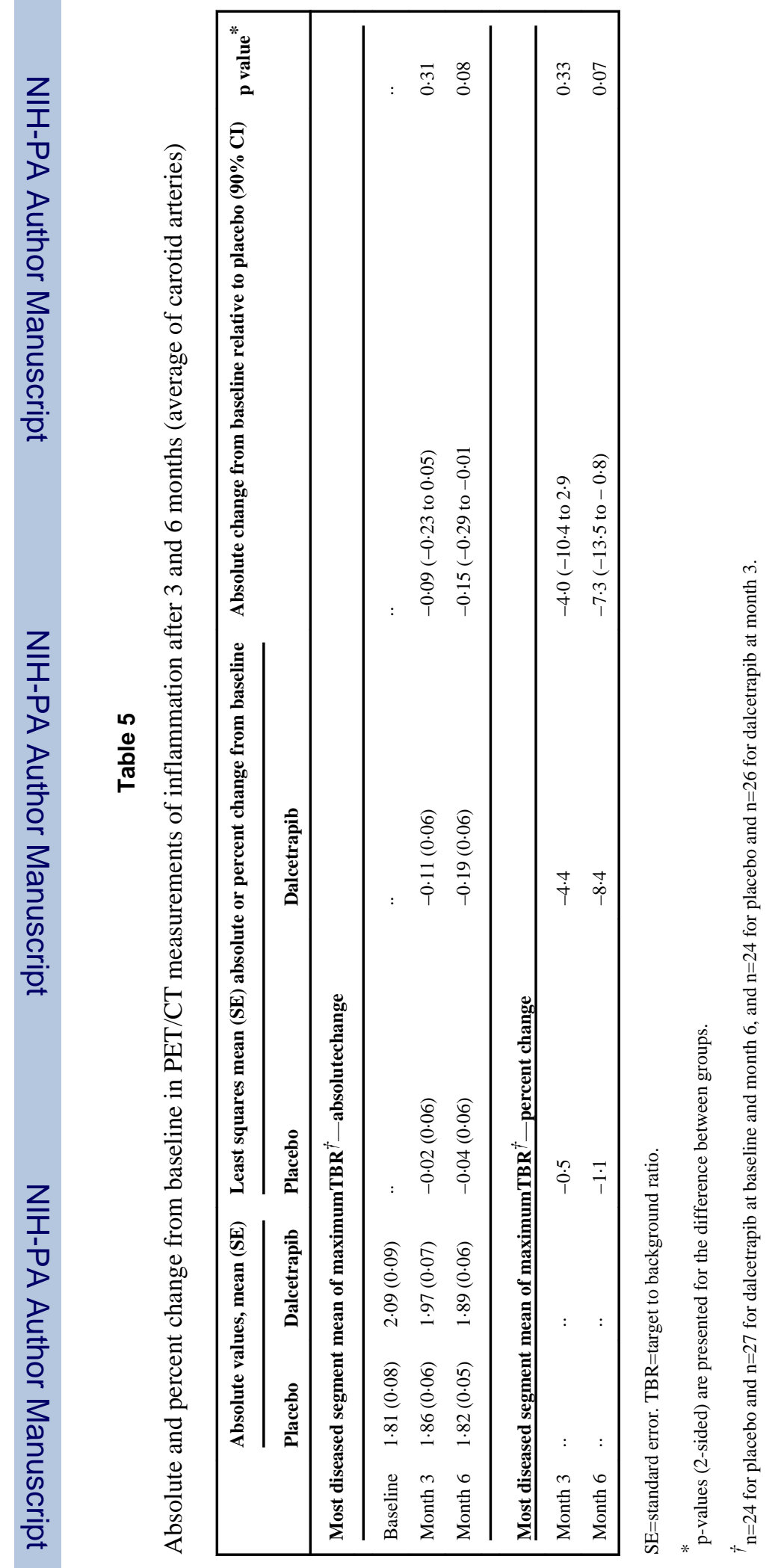


Table 6

Adverse events, safety variables, and adjudicated cardiovascular events throughout the study

\begin{tabular}{|c|c|c|}
\hline & Placebo $(n=65)$ & Dalcetrapib $(n=63)$ \\
\hline \multicolumn{3}{|l|}{ Patients with adverse events } \\
\hline At least one adverse event & $59(91 \%)$ & $56(89 \%)$ \\
\hline Drug-related adverse event & $18(28 \%)$ & $11(17 \%)$ \\
\hline Clinical adverse event leading to discontinuation of study drug* & $2(3 \%)$ & $1(2 \%)$ \\
\hline Drug-related adverse event leading to discontinuation of study drug & $5(8 \%)$ & $4(6 \%)$ \\
\hline Serious adverse event & $13(20 \%)$ & $12(19 \%)$ \\
\hline Drug-related serious adverse event & $2(3 \%)$ & 0 \\
\hline Diarrhoea & $4(6 \%)$ & $5(8 \%)$ \\
\hline Dizziness & $5(8 \%)$ & $3(5 \%)$ \\
\hline \multicolumn{3}{|l|}{ Key safety variables } \\
\hline Patients with increase to high ${ }^{\dagger}$ systolic BP & $20(31 \%)$ & $18(29 \%)$ \\
\hline Patients with increase to $\operatorname{high}^{\dagger}$ diastolic BP & $8(12 \%)$ & $11(17 \%)$ \\
\hline Patients with decrease to low systolic BP & $13(20 \%)$ & $10(16 \%)$ \\
\hline Patients with decrease to low diastolic BP & $10(15 \%)$ & $12(19 \%)$ \\
\hline \multicolumn{3}{|l|}{ Adjudicated cardiovascular events $\S$} \\
\hline Patients with event & $7(11 \%)$ & $2(3 \%)$ \\
\hline \multicolumn{3}{|l|}{ In all three cases the clinical adverse event was death (see text). } \\
\hline \multicolumn{3}{|c|}{${ }^{\dagger}$ High BP: systolic $\geq 180 \mathrm{~mm} \mathrm{Hg}$ or $\geq 20 \mathrm{~mm} \mathrm{Hg}$ increase from baseline; diastolic $\geq 105 \mathrm{~mm} \mathrm{Hg}$ or $\geq 15 \mathrm{~mm} \mathrm{Hg}$ increase from baseline. } \\
\hline \multicolumn{3}{|c|}{ Low BP: systolic $\$ 90 \mathrm{~mm} \mathrm{Hg}$ or $\geq 20 \mathrm{~mm} \mathrm{Hg}$ decrease from baseline; diastolic $\$ 50 \mathrm{~mm} \mathrm{Hg}$ or $\geq 15 \mathrm{~mm} \mathrm{Hg}$ decrease from baseline. } \\
\hline
\end{tabular}

